\title{
Evaluation of the Management of Family Physicians Health Care Services to Diabetic Patients in Rural Areas of Northern Iran
}

\author{
Ghahraman Mahmodi', Melody Omraninava ${ }^{*}$, \\ Bahman Nikpour ${ }^{1}$, Eissa Omidi Qasemabad ${ }^{2}$ \\ ${ }^{1}$ Hospital Administration Research Center, Sari Branch, Islamic Azad University, Sari, Iran \\ ${ }^{2}$ Health Services Management, Sari Branch, Islamic Azad University, Sari, Iran \\ Email: *melodyomraninava@yahoo.com
}

How to cite this paper: Mahmodi, G., Omraninava, M., Nikpour, B. and Qasemabad, E.O. (2018) Evaluation of the Management of Family Physicians Health Care Services to Diabetic Patients in Rural Areas of Northern Iran. International Journal of Clinical Medicine, 9, 92-103.

https://doi.org/10.4236/ijcm.2018.92010

Received: December 30, 2016

Accepted: February 21, 2018

Published: February 24, 2018

Copyright $\odot 2018$ by authors and Scientific Research Publishing Inc. This work is licensed under the Creative Commons Attribution International License (CC BY 4.0).

http://creativecommons.org/licenses/by/4.0/

\begin{abstract}
Background and Objectives: The ultimate goal of the health system is to improve the health status of people. To achieve this goal and meet the needs and expectations of people in the field of health, different strategies have been designed, one of which is the family physician. Therefore, the main aim of this study was to evaluate management and performance of the family physician in the diagnosis, treatment and prevention of diabetes in the Counties of Gilan Province. Materials and Methods: This is a cross-sectional study, which was carried out descriptively. In this study 320 patients with diabetic records were selected from among 1900 using simple random selection. Results: There is a significant difference between the number of visits, the number of referrals to specialists and the number of tests with the expected rate. In addition, $68.8 \%$ of patients were diagnosed by the family physician for the first time. According to comparisons made on the number of referrals, visits and request for blood tests, there was a significant difference between two Counties $(p<0.05)$. Conclusion: The results of the present study indicate that there is a fundamental weakness in terms of diagnosis, control, care of patients, referral, completion of health records and eventually preventing diabetes complications in the northern villages of Iran. In general, family physician program has relatively good performance in Iran after several years, but has not been able to reach the determined goals and standards.
\end{abstract}

\section{Keywords}

Family Physician, Diabetes, Health System, Referral System 


\section{Introduction}

Diabetes mellitus is a metabolic disorder that results from defects in insulin secretion, or action, or both. This disease is characterized by high blood sugar (glucose) with disturbances in protein, fat and carbohydrate metabolism. Symptoms of diabetes mellitus include polyuria (increase urination), polydipsia (increased thirst) and polyphagia (increased hunger) [1]. Persistent hyperglycemia in diabetes mellitus leads to dysfunction and malfunctioning of numerous organs such as nerves (diabetic neuropathy), kidneys (diabetic nephropathy), eyes (diabetic retinopathy) and heart (mainly myocardial infarction) [2]. The prevalence rate of diabetes is different in various countries and societies, which ranges from $1 \%$ to $25 \%$ [3]. In Iran, more than $15 \%$ of men and $30 \%$ of women are at risk of diabetes and the prevalence of diabetes in rural areas is less than that in urban areas [4]. The prevalence of diabetes has been on the increase in recent years and it will become an epidemic disease in the future [5].

Diabetes affects patients in various aspects including physical, psychological and social. Therefore, good control of the disease is one of the most important objectives of the national health system interventions in the country. However, it is not a simple process and requires informed and timely interventions, proper periodical management, and appropriate cares for all lifetime [6]. In this approach, the family physician is considered as the main basis of health care systems in many countries. The family physician is responsible for providing health services defined within the package to individuals, families and population without discrimination of age, gender, socio-economic characteristics and morbidity risks [7]. The family physician helps improve patients' health through more and better relationship with them and their families [8].

Family physicians should know appropriate methods of screening and diagnostic tests and should be able to effectively perform necessary tests in people prone to diabetes, and recommend and implement appropriate methods for primary prevention by improving lifestyles. They should also periodically carry out the necessary examinations in diabetic patients, and reduce diabetic complications by strict control of blood sugar and risk factors of non-communicable diseases using a comprehensive management. They should also be able to reduce the development of chronic complications, if any, utilizing comprehensive care program [9]. The duty of the family physicians is not merely limited to the diagnosis and treatment of diseases, rather than preventing this type of diseases associated with lifestyles should be their primary duty. However, there are few studies related to family physician management and diabetes in Iran and the quality of diabetes care [10].

Diabetes is one of the health care priorities in Iran, an effective step for diagnosis, care and prevention of which will be very important. Regarding the duties defined for family physicians and the lack of adequate research in this field, we decided to measure the performance of family physician in fields of diagnosis, care and prevention of diabetes in Roudsar and Amlash Counties of Gilan Province. 
The results of this research could be used by managers in their decision-making process in order to promote and improve healthcare sector [11].

\section{Methods}

Studied population: This is a cross-sectional study carried out in 21 rural healthcare systems in Roudsar and Amlash Counties from 2008 to 2015.This research lacked the characteristics of a cohort study, especially the case and control groups, in which the cases are exposed to the disease and the controls are not. All samples were diabetics and had a health record. The sample size was calculated based on Morgan Table and 320 randomly selected patients with diabetic records were studied. Most patients had type 2 diabetes and 74\% were over 50 years old, and according to the Ministry of Health, HbAlc was requested in $84.1 \%$ and FBS in $96.3 \%$ of them. Meanwhile, their weight and blood pressure were controlled. About $50.6 \%$ of diabetic patients in the study had active complications which commonly included neural, ocular, cardiovascular, renal complications and ultimately diabetic ulcers (diabetic foot).

In terms of socioeconomic status, all were covered by health insurance, $48.8 \%$ were housewives and the rest were employed, $22.2 \%$ were smokers, and $68.8 \%$ were detected by family physicians and the remainder in private sector or hospital. Code of Ethics Committee is IR.IAU.SARI.REC.1396.40. Inclusion criteria were: a) All diabetic patients with a health record; b) Records existing only in rural health centers.

\subsection{Data Collection Tool}

To collect data, two check-lists and one researcher-made questionnaire were used. One of the check lists relates to the health house, which contains 10 questions related to the diagnosis, filing year, the time intervals between visits to health houses, blood tests, record of weight, blood pressure and referral to a specialist. The second check-list relates to health records filed at the health-care centers and the family physician. According to the information contained in health records, the status of completion of records, records of training measures, referrals, visits, weight, and complications were extracted.

The patient questionnaire was completed with the help of professionals and experts in the same center and through face to face interview with patients.

\subsection{Evaluating the Validity and Reliability of the Questionnaire}

In order to validate the questionnaire assessing the management of the family physician services regarding the diagnosis, treatment and prevention of diabetes complications, 10 professionals and experts in the field of family physician completed the questionnaire to determine the content validity ratio and content validity index. The content validity ratio (CVR) and content validity index (CVI) were calculated as 0.62 and 0.98 respectively, after completing the questionnaire by the 10 experts, the necessary modifications were made. To assess the reliability 
of the questionnaire, sixteen patients were simultaneously interviewed by two disease experts. Afterwards, each qualitative question was assessed based on the kappa coefficient. The kappa value of qualitative questions was about $90 \%$, which represents an acceptable agreement to measure the clients in question. Also, intraclass correlation coefficient was utilized to assess quantitative questions. The agreement value for the related questions was more than $85 \%$, which represents the acceptable agreement of the answers. To assess the internal reliability of questions and dual-mode questions, Cronbach's alpha and Richardson 20 coefficients were utilized, respectively. In addition, external reliability was assessed using test-Retest or Pearson correlation coefficient.

\subsection{Data Analysis}

Statistical analysis was conducted using SPSS version 21. To describe data, the frequency, frequency percentage as well as statistical indices of mean and standard deviation and linear diagrams were used. To compare the obtained values with the expected values, one sample t-test was used. To compare the activity level in both Roudsar and Amlash Counties, independent t-test was used. In this study, $\mathrm{p}<0.05$ was considered statistically significant.

\section{Results}

Demographic data of patients are summarized in Table 1, in which it can be seen that $68.8 \%$ and $31.3 \%$ of patients were from Roudsar and Amlash Counties, respectively. Most patients were aged between 60 - 69 years

All the studied patients had health records. The number of patients who had complete records was 129 (40.3\%). More importantly, only 14.7\% of the health records were completed in terms of diabetes care training and more than $59 \%$ of them were incomplete in this regard. Moreover, no preventive training measure was recorded in $26 \%$ of health records. Furthermore, HbAlc test was requested for $84 \%$ of the patients in the Health House at least once a year. However, it is unclear how many of them have been tested, which is a limitation of the study.

Figure 1 shows that blood test requests has an upward trend in total compared with previous years, except for 2011, the reasons of which is unclear. The minimum and maximum blood test request was 0 and 4 times, respectively.

So the mean ranges from $0.6 \%$ to $1.35 \%$. In general, more than $91 \%$ of patients are referred to a specialist at least once by the health house family physician. As indicated in Figure 2, the mean number of referrals ranges from 1 to 1.48 and have been inconsistent over the years, while $95.6 \%$ patients were referred by the health-care center physician to the second level referral system at least once. Table 1 contains information presented to the health-care employee by the patient while completing the questionnaire.

According to Table 2, 75\% of the patients said that they recognize their family physician and are under their treatment but $22 \%$ of the patients, despite having medical records or health records, stated that they are not supported by the family 
physician. Moreover, $71 \%$ of the patients said that their disease has been diagnosed by the family physician for the first time. In addition, $74 \%$ of the patients were aware that they should always visit the health-house at least once a month for disease control. Moreover, slightly more than $50 \%$ of the patients are aware that they should necessarily and inevitably be visited by the family physician four times a year. Patients while completing the questionnaire gave the following reasons for their inability to visit the health houses or health-care centers on time: Lack of adequate time (53\%), being treated by a specialist (20\%), high costs (3.6\%) and disability (23.4\%). Furthermore, $51 \%$ of the patients interviewed were experiencing the side-effects of diabetes, half of whom were suffering from

Table 1. Baseline demographics of study participants.

\begin{tabular}{|c|c|c|c|}
\hline & & Number & Percentage (\%) \\
\hline \multirow[b]{2}{*}{ County } & Roudsar & 220 & 68.8 \\
\hline & Amlash & 100 & 31.3 \\
\hline \multicolumn{4}{|c|}{ Age (Mean $\pm S D$, Maximum and Minimum) } \\
\hline \multirow{4}{*}{ Age group (years) } & $<50$ & 83 & 25.9 \\
\hline & $50-59$ & 51 & 15.9 \\
\hline & $60-69$ & 119 & 37.2 \\
\hline & $>70$ & 67 & 20.9 \\
\hline \multirow{4}{*}{ Gender } & Male & 136 & 42.5 \\
\hline & Female & 184 & 57.5 \\
\hline & Illiterate & 162 & 50.6 \\
\hline & Primary & 121 & 37.8 \\
\hline \multirow[t]{3}{*}{ Literacy } & High school degree & 37 & 11.6 \\
\hline & Associate's degree & 0 & 0 \\
\hline & Bachelor's degree or higher & 0 & 0 \\
\hline \multirow{5}{*}{ Smoking status } & Yes & 71 & 22.2 \\
\hline & No & 249 & 77.8 \\
\hline & Employee & 9 & 2.8 \\
\hline & Laborer & 10 & 3.1 \\
\hline & Self-employed & 26 & 8.1 \\
\hline \multirow[t]{6}{*}{ Job status } & Housekeeper & 156 & 48.8 \\
\hline & Student & 1 & 0.03 \\
\hline & farmer & 98 & 30.6 \\
\hline & Others & 20 & 6.3 \\
\hline & Health care and rural insurance & 205 & 64.1 \\
\hline & Military health insurance & 45 & 14.1 \\
\hline \multirow{2}{*}{ Health insurance } & Social support insurance & 70 & 21.9 \\
\hline & Others & 0 & 0 \\
\hline
\end{tabular}




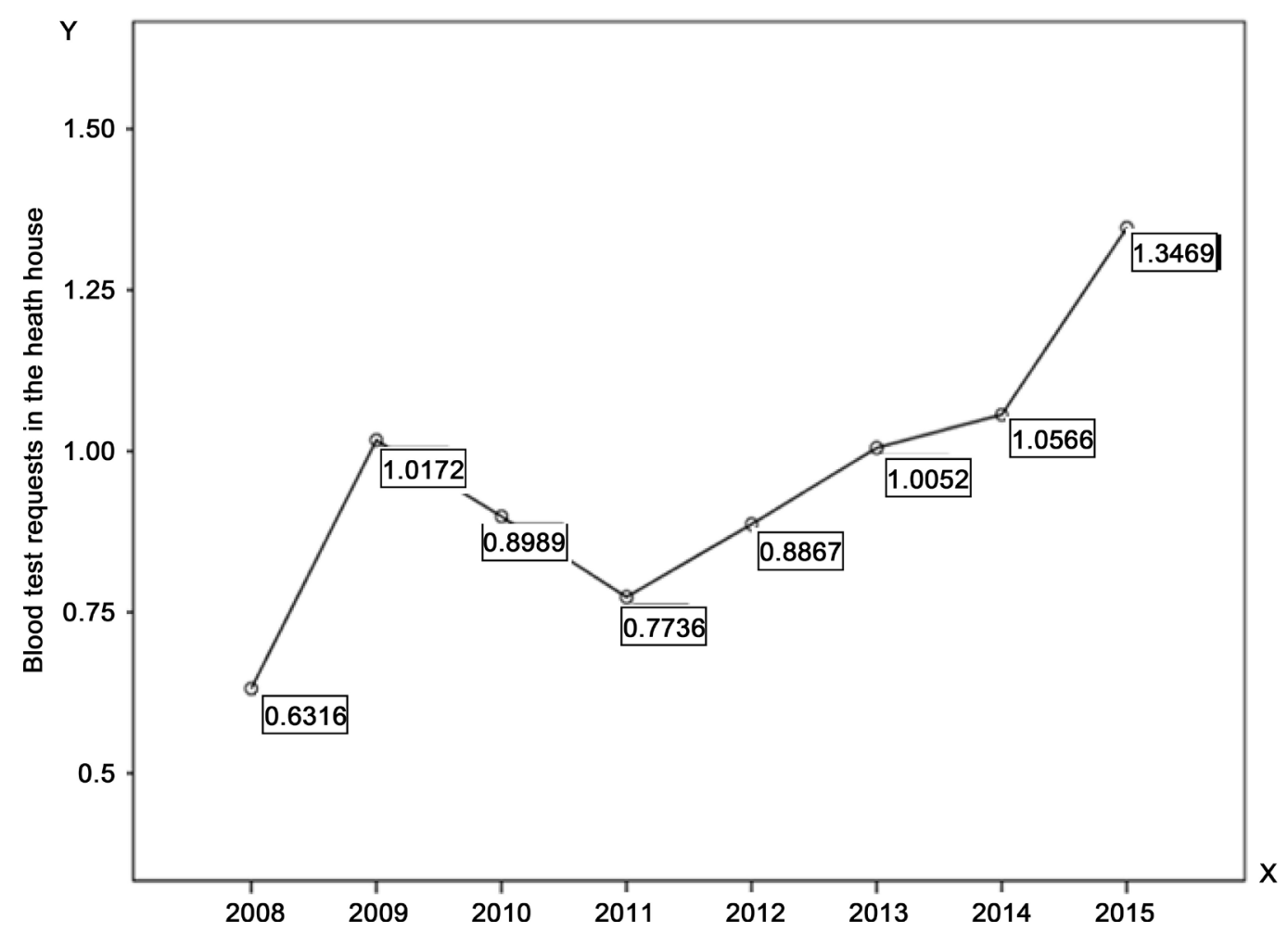

Figure 1. Blood test requests in the health house.

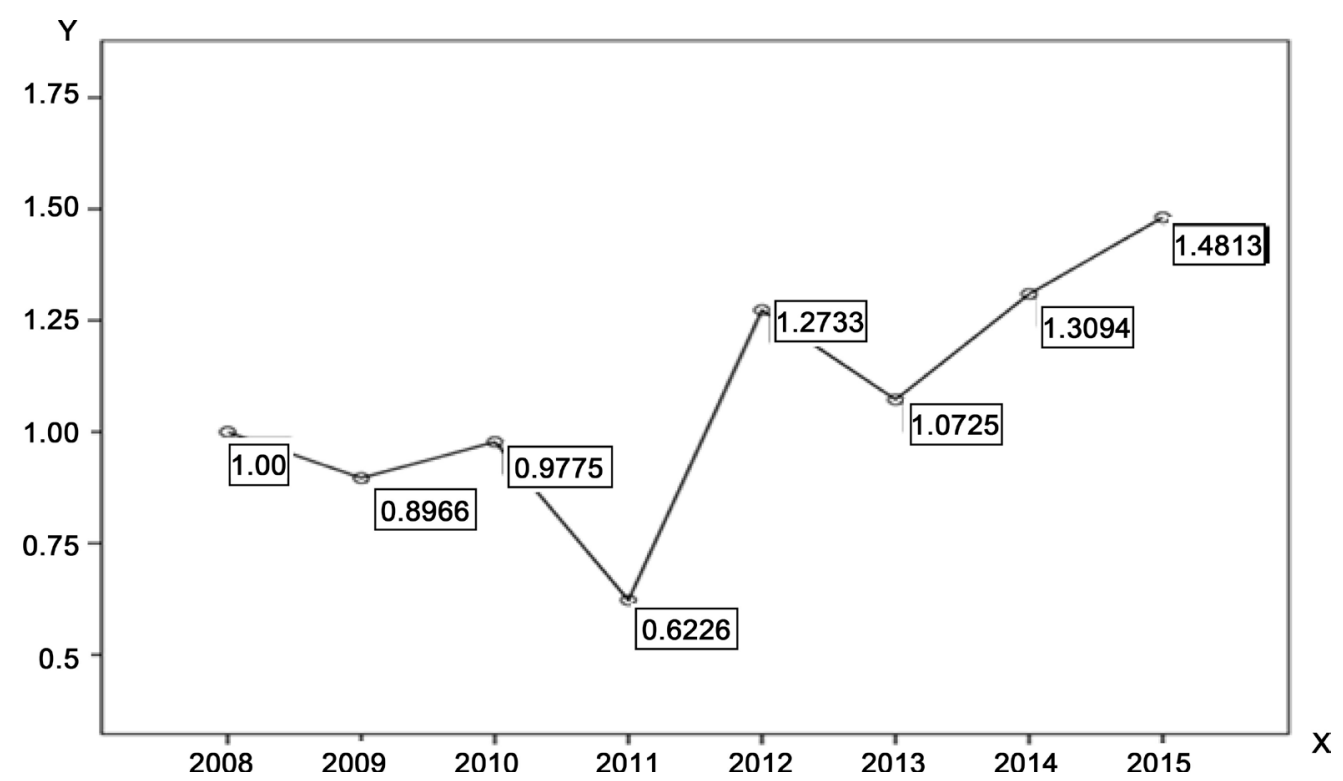

Figure 2. Refer to specialist by health-house family physician.

neurological side-effects. Some of the patients (61.6\%) believed that both drug consumption and following a diet and exercise program are equally important in controlling and preventing diabetes.

Mean visit times and mean referrals to health house were statistically significant separately for the studied years compared with the expected rate (at least 4 times a year) $(\mathrm{p}<0.0001)$ (Figure 3$)$. 
Table 2. Questionnaire.

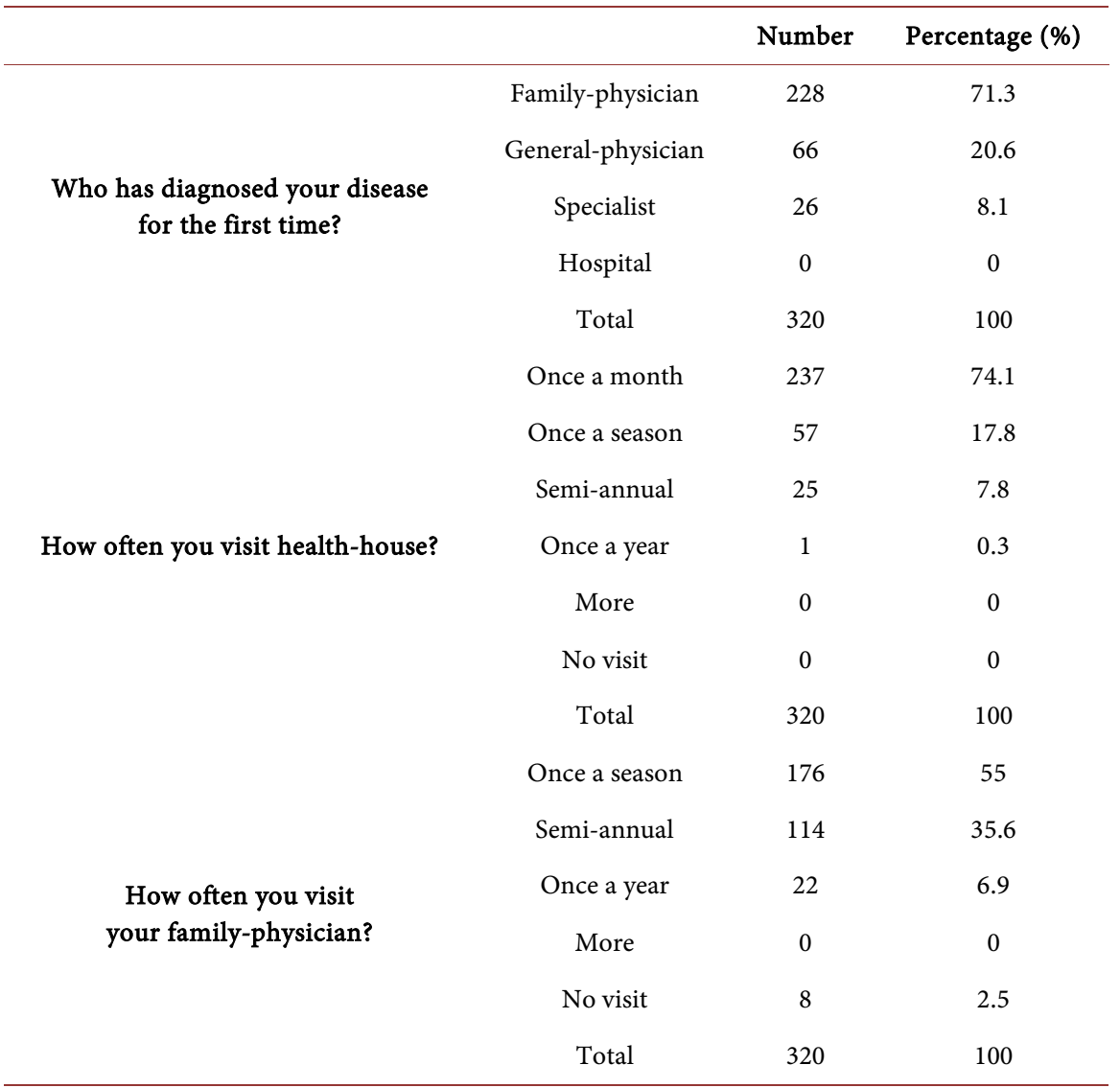

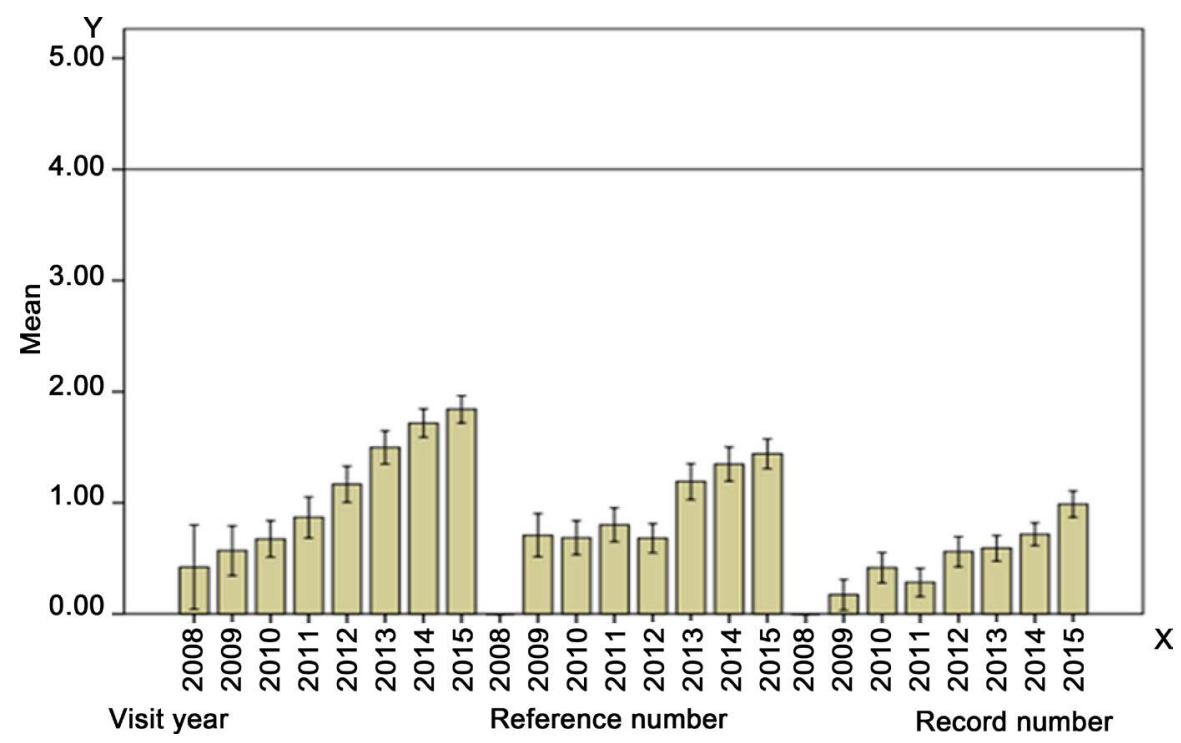

Figure 3. Visit and referral status.

Therefore, the referral rate (mean) was less than the expected rate. The mean number of referrals, as well as the frequency of test request and referral was statistically significant compared with the expected rate, separately for all the studied years $(p<0.0001)$. The number of referrals and the test request is less than 
the expected number in all the years. The results of comparison between the number of visits and test requests and referral in both Roudsar and Amlash Counties showed that the number of visits in Roudsar County was more than that in Amlash during the studied years in such a way that this difference in 2009, 2010, 2011,2012, 2013, 2014 and 2015 was statistically significant ( $\mathrm{p}<$ 0.05). In addition, the number of test request was higher in Roudsar than in Amlash in all the years except in 2015 such that this difference was statistically significant in 2009 and 2011 ( $p<0.05)$. But the number of test request in 2015 was higher in Amlash County compared with that of Roudsar, such that it was statistically significant $(\mathrm{p}=0.044)$. In addition, the number of referrals was higher in Roudsar compared with that in Amlash in 2009 and 2010 but in the following years (2011, 2012, 2013 and 2014) the number of referrals in Amlash was more than in Roudsar, which was statistically significant $(\mathrm{p}<0.0001)$.

\section{Discussion}

Generally, the family physician program after a few years of its implementation in Iran performed relatively well, but the referral system is still not properly implemented and feedbacks from specialists are not sent to family physicians, Moreover, a small percentage of submitted feedbacks has good quality. Also, the performances of health teams and family physicians were weak in referring the patients and tracking the outcome of the disease. Although the program somewhat improved access and reduced unnecessary costs, it failed to reach the determined goals and standards.

Measuring the case-finding rate of the family physician team as a strategy for earlier diagnosis of this common chronic disease can be considered as a criterion to measure the performance of the family physician in performing duties entrusted to them. Our study revealed that $68.8 \%$ of diabetic patients have been diagnosed for the first time by the family physician. In addition to, the studies of Lebaron et al. [12], Devlin et al. [13], Aalaei [14] and Khadivi [15] approved the diagnosis of a high percentage of patients for the first time by their family physicians. As a result of the latent nature of the chronic disease symptoms, and their progressive course of chronic and irreversible complications, it seems that these results are considered as important and positive achievements following the implementation of family physician program in terms of cost-effectiveness analysis. Because early diagnosis and continuity of patients care (training lifestyle modification, disease treatment and controlling its associated complications) will improve the health conditions of patients both in quantitative and qualitative aspects of life.

According to physicians, Filing health records are the benefits of family physician program, but there have been the fundamental shortcoming in its completion. In filing health records for the families covered by the insurance, screening people at risk for diseases that are top priority especially diabetes, and as well as the process of care and prevention of complications of these diseases are the duty 
of family physicians. In this study, it was found that almost $100 \%$ of the patients have health care records at health care centers, but there is a fundamental shortcoming in completion of health records, recording the medical history of disease and personal characteristics, and as well as health education and prevention services, which make it difficult to achieving the objectives of the health program. The results of the present study are consistent with Jabari et al. [16] and Nasrollahpour [17], while it was inconsistent with the results of Borhaninejad [18]. This might be probably due to the completion of health records, which is a paper process and not electronic, it is cumbersome, and despite the importance of the work, the data record is less than the actual amount, thus reducing access to real information.

Three indexes including the number of visits, number of laboratory test requests and patient referral rates to the second level were used to determine the success rate of performed services to prevent the complications of the disease. With respect to the number of visits of patients by the family physician, our study shows that less than half of the patients were visited or taken care of twice a year. In the process of patient care and prevention of disease complications, Patel et al. [19], Jahanfar et al. [20] and Lindström et al. [21] obtained results similar to the results of our research, and no study was reported to be inconsistent with our research. The results of our study show that the number of laboratory test requests is very low compared with the predefined goals and standards. With respect to the number of laboratory test requests, the studies of Nagpal et al. [22] and Jahanfar et al. point out the deep gap between the guidelines and offered services.

Moreover, the present findings suggest that the referral to the second level is also significantly different from the defined standards. So that, the management process of the family physician is not in good condition. Studies carried out by Kabir et al. [23], Ashrafian et al. [24], Jabari et al. [25], Chaman et al. also referred to this poor conditions; however, the results of studies carried out by Rouhani et al. [26], Shafiei et al. [27] and Lebaron et al. [28] were inconsistent with our results. Generally, it can be concluded that there have been poor performance in the health team in connection with the care of diabetic patients in order to prevent complications, which were previously mentioned in some studies [29].

In this study, a significant difference between the two Counties of Roudsar and Amlash was observed in the results obtained from the comparison of different indices [30]. It is clear from the study that the number of referrals and visits in Roudsar was higher than in Amlash over the studied years. Moreover, the number of laboratory test requests in Roudsar was higher than in Amlash in most all the years, except 2015. However, the number of referrals in Amlash was higher than that in Roudsar in recent years [31].

\section{Conclusions}

The results of this research show the fundamental weakness of the family physician 
program in the diagnosis, control, treatment, referral, health records completion and ultimately prevention of complications. At present, in the Iranian care system, referral of patients to higher levels and reflection of feedback to the lower levels, as well as elimination of drug and laboratory equipment deficiencies are improving.

To improve the performance of the health team, it is recommended that health records should be completed electronically using appropriate software, remove the referral limitation (a maximum of $10 \%$ of the visited patients can be referred to the second level) for chronic patients. In addition, considering the high diagnostic value of the $\mathrm{HbA1c}$ test and glucometer in diabetic patients, it is recommended that the possibility of performing such test be provided in health centers, and extensive researches be effectively carried out in this field in other parts of the country.

Research limitations included: 1) According to the instructions of the Ministry of Health, the family doctor and the Health Insurance Supervisory Unit can refer a maximum of $10 \%$ of the visited patients to the second level; 2) Relatively weak feedback from the second level to the first level.

\section{References}

[1] Pozzo, M.J., Mociulsky, J., Martinez, E.T., Senatore, G., Farias, J.M., Sapetti, A., et al. (2016) Diabetes and Quality of Life: Initial Approach to Depression, Physical Activity, and Sexual Dysfunction. American Journal of Therapeutics, 23, e159-e171. https://doi.org/10.1097/01.mjt.0000433949.24277.19

[2] Tao, Z., Shi, A. and Zhao, J. (2015) Epidemiological Perspectives of Diabetes. Cell Biochemistry and Biophysics, 73, 181-185. https://doi.org/10.1007/s12013-015-0598-4

[3] Nesary, M.Z.M., Rajab, A., Feghihzadeh, S., Basamour, S. and Rahmani, M. (2009) The Impact of Telephone Follow-Up of Nurse on the Control of Blood Glucose and Lipid in Patients with Diabetes Type 2. Iranian Journal of Diabetes and Lipid Disorders, 8, 115-122.

[4] Azimi-Nezhad, M., Ghayour-Mobarhan, M., Parizadeh, M., Safarian, M., Esmaeili, H., Parizadeh, S., et al. (2008) Prevalence of Type 2 Diabetes Mellitus in Iran and Its Relationship with Gender, Urbanisation, Education, Marital Status and Occupation. Singapore Medical Journal, 49, 571.

[5] Shaw, J.E., Sicree, R.A. and Zimmet, P.Z. (2010) Global Estimates of the Prevalence of Diabetes for 2010 and 2030. Diabetes Research and Clinical Practice, 87, 4-14. https://doi.org/10.1016/j.diabres.2009.10.007

[6] Handelsman, Y., Bloomgarden, Z.T., Grunberger, G., Umpierrez, G., Zimmerman, R.S., Bailey, T.S., et al. (2015) American Association of Clinical Endocrinologists and American College of Endocrinology-Clinical Practice Guidelines for Developing a Diabetes Mellitus Comprehensive Care Plan-2015-Executive Summary. Endocrine Practice, 21, 413-437. https://doi.org/10.4158/EP15672.GL

[7] Hashjin, A.A., Gorji, H.A., Kringos, D.S., Delgoshaei, B., Manoochehri, J. and Klazinga, N.S. (2015) A General Description of the Iranian Health Care System. Quality Assurance Strategies in Hospitals, 21.

[8] Giguere, A.M., Labrecque, M., Borduas, F. and Rouleau, M. (2015) Effectiveness of Monetary Incentives to Recruit Family Physicians as Study Subjects: A Randomized 
Controlled Trial. BMC Research Notes, 8, 1-4.

https://doi.org/10.1186/s13104-014-0969-8

[9] Shams, M., Soveid, M., Imanieh, M.H. and Moghadami, M. (2015) Screening Type 2 Diabetes: A Clinical Guide for Family Physicians. Journal of Health Sciences and Surveillance System, 3, 125-127.

[10] Ebrahimi, H., Emamian, M.H., Shariati, M., Hashemi, H. and Fotouhi, A. (2015) Diabetes Mellitus and Its Risk Factors among a Middle-Aged Population of Iran, a Population-Based Study. International Journal of Diabetes in Developing Countries, 36, 189-196.

[11] Krejcie, R.V. and Morgan, D.W. (1970) Determining Sample Size for Research Activities. Educational and Psychological Measurement, 30, 607-610. https://doi.org/10.1177/001316447003000308

[12] Lebaron, S. and Schultz, S. (2005) Family Medicine in Iran: The Birth of a New Specialty. Family Medicine, 37, 502-505.

[13] Devlin, R.A. and Rudolph-Zbarsky, J. (2014) Social Networks and the Probability of Having a Regular Family Doctor. Social Science \& Medicine, 115, 21-28. https://doi.org/10.1016/j.socscimed.2014.05.057

[14] AalaeiArdakani, M., Hesam, S. and Vahdat, S. (2014) Assessment of the Effect of Family Physician on the Management Indices of Health Care in the Rural Health-Treatment Centers in the Province of Yazd in 2013. Tolooebehdasht, 12, 192-203.

[15] Khadivi, R., Hashemi, T., FarrokhSiar, E. and Rohani, M. (2012) The Assessment of Family Physicians' Performance in Screening of Hypertension and Diabetes Mellitus in Rural Areas of Isfahan County: A 5-Year Survey. Journal of Isfahan Medical School, 30, 1650-1661.

[16] Jabari, A., Sharifirad, G., Shokri, A., Ziari, N.B. and Kordi, A. (2013) Overview of the Performance of Rural Family Physician in Iran. Health Information Management, 9, 1132-1145.

[17] NasrollahpourShirvani, S.D. (2014) The Implementation of Family Physician Program in I.R. Iran: Achievements and Challenges. Journal of Babol University of Medical Sciences, 16, 15-26.

[18] Borhaninejad, V., Pourebrahimi, M.H., Nadrian, H., Iranpour, A., Tabe, R. and Hasani, K.M. (2015) Satisfaction of Service Recipients of Family Physician Program in Kerman, 2011. Journal of Health and Development, 4, 1-9.

[19] Patel, M., Patel, I.M., Patel, Y.M. and Rathi, S.K. (2012) Factors Associated with Consumption of Diabetic Diet among Type 2 Diabetic Subjects from Ahmedabad, Western India. Journal of Health, Population and Nutrition, 30, 447-455.

[20] Jahanfar, M., Yaghmaei, F., AlaviMajd, H. and Afkhami, M. (2014) Attitude toward Preventive Behavior of Complications in Type 2 Diabetics. Journal of Health Promotion Management, 3, 43-53.

[21] Lindström, J., Eriksson, J.G., Valle, T.T., Aunola, S., Cepaitis, Z., Hakumäki, M., et al. (2003) Prevention of Diabetes Mellitus in Subjects with Impaired Glucose Tolerance in the Finnish Diabetes Prevention Study: Results from a Randomized Clinical Trial. Journal of the American Society of Nephrology, 14, S108-S113. https://doi.org/10.1097/01.ASN.0000070157.96264.13

[22] Nagpal, J. and Bhartia, A. (2006) Quality of Diabetes Care in the Middle- and High-Income Group Populace the Delhi Diabetes Community (DEDICOM) Survey. Diabetes Care, 29, 2341-2348. https://doi.org/10.2337/dc06-0783 
[23] Kabir, M.J., Jafari, N., NahimiTabihi, M., Mikaniki, E., Ashrafian Amir, H., DavoudNasrollahpourShirvani, S., et al. (2015) Health Record and Recording the Services Provided in Centers Implementing Rural Family Physician and Insurance Program in Northern Provinces of Iran. Hospital, 14, 61-69.

[24] AshrafianAmiri, H., Shirvani, N., Davood, S. and Malegzadeh, R. (2015) Performance of Family Physicians (FPS) from Viewpoint of Managers and Experts of Northern Provinces of Iran. Journal of Babol University of Medical Sciences, 17, 79-85.

[25] Chaman, R., Amiri, M., Raei, M., Alinejad, M. and Nasrollahpour, S.S. (2011) National Family Physician Program in Shahroud: Assessing Quality of Implementation and Condition of Settings. Hakim Research Journal, 14, 123-129.

[26] Rouhani, S., Rezaei, K., Ali-MohammadPour, R., Parvar, R. and Rajabi, S. (2011) Management of Patients with Diabetes Mellitus in the Rural Areas. Journal of Health and Care, 13.

[27] Shafiei, F., shahgholian, N., Amini, M., Abazari, P. and Amini, P. (2012) Barriers to Blood Glucose Level Management in the Health Care System: View Points of Patients, Families and Medical Personnel. Iranian Journal of Endocrinology and Metabolism, 14, 25-31.

[28] Lebaron, S. and Schultz, S. (2005) Family Medicine in Iran: The Birth of a New Specialty. Family Medicine, 37, 502-505.

[29] Janati, A., Maleki, M.R., Gholizadeh, M., Narimani, M. and Vakili, S. (2010) Assessing the Strengths \& Weaknesses of Family Physician Program. Knowledge \& Health Journal, 4, 39-44.

[30] NasrollahpourShirvani, S. and Mohoudi, S. (2013) Evidence-Based Policymaking in Health System and Its Achievements and Challenge in Iran. Babol University of Medical Sciences, Babol.

[31] Delpisheh, A., Azizi, H., Dantalab Esmaeili, E., Haghiri, L., Karimi, G. and Abbasi, F. (2016) The Quality of Care and Blood Sugar Control in Type II Diabetic Patients of Rural Areas under the Care by Family Physicians. Iranian Journal of Diabetes and Metabolism, 14, 189-198. 